\title{
Protection of the waterfront panoramas based on computational 3D-analysis
}

\author{
Pawel Rubinowicz ${ }^{1}$ \\ ${ }^{1}$ West Pomeranian University of Technology, Szczecin \\ 'pawel@rubinowicz.com.pl
}

The article presents the application of the Visual Protection Surface (VPS) method in protecting waterfront panoramas. The digital analysis of visual impact, which is most frequently used in urban planning, assesses the impact of new investment on the cityscape. The study presented in the article is based on a reverse approach-determining the maximum height of buildings so new facilities do not distort protected vistas in a city, vistas which are crucial for the preservation of the city's cultural identity and spatial identification. The assessment of the application is based on a case study of Gdansk, Poland, where a 3D LiDAR model was used. The study involved the use of software developed by the author $(C++)$. It also analyzed VPS input parameters. Conclusions can be used to assess and verify analysis findings with different software (GIS/CAD). The article shows the potential application of the VPS method in urban planning.

Keywords: computational urban analyses, urban landscape protection, strategic views, tall buildings, 3D city models, VPS method

\section{INTRODUCTION}

The area of research discussed in the article covers the use of digital analyses of cityscapes for the purpose of urban and spatial planning. Simulations are based on 3D city models which availability, accuracy and relevance have been steadily growing. The potential enables to introduce various visibility analyses that are discussed in literature and used in planning practice. This enhances the possibility of cityscape development while taking care of major values of city panoramas and views. Hence, the development of facilities in harmony with the existing cityscape has become an obvious priority in planning. Tall building, in particular, are a source of major risk. According to current statistics, we witness unprecedented rapid development of those building facilities globally as well as in European cities [1].

Digital analysis of visual impact, which is most frequently used in urban planning, assess the impact of new investment projects (including tall buildings) on the cityscape. Relevant analytical techniques are now sufficiently (Caha 2017, Danese et al. 2009). The goal of the study presented in the article is based on a reverse approach and focuses on determining city development principles that later help preserving integrity of valuable waterfront panoramas. Results of computer simulations are then used to calculate maximum permitted height of buildings in a city, which prevent any deterioration of historical cityscapes, in particular those that can be seen from waterfronts, by new investment.

Goals implemented by the study: 
1. Presentation of the simulation process (Chapter: "Methodology \& digital resources")

2. Study of the issue in a selected city - Gdansk, Poland (Chapter: "Case Study")

3. Assessment of results and input parameters (Chapters: "Case Study" \& "Results and Discussion")

4. Assessment of the possibility of using the method in urban planning (Chapter: "Results \& Discussion")

\section{METHODOLOGY \& DIGITAL RESOURCES}

The study uses the Visual Protection Surface (VPS) method, developed by author (Czyńska, Rubinowicz 2015). The method was used based on LiDAR could of points model, or more precisely the Digital Surface Model (DSM). The VPS has been described in Chapter: "VPS method", and the model used presented in Chapter "Applied 3D-City-Models". All simulations referred to in the article are developed using $\mathrm{C}++$ software developed by the author, which was used at all stages of the implementation of the proposed method.

\section{VPS METHOD}

The VPS method used in the study to analyze a broad cityscape. The goal is to examine geometrical relationships between the scope of visual protection of the city and the maximum heights of new buildings. The input data include coordinates for a number of strategic views that need to be protected. Results achieved is the surface above the city defining the maximum height of buildings in such a way that no new facility can be seen in any of selected strategic views (Czyńska, Rubinowicz 2015; Rubinowicz, Czyńska 2015).

The VPS method can be used for precise calculation of the maximum height of new buildings in each location within the investigated area of a city. The maximum height is determined with the goal of protecting strategic views against their distortion by new buildings (new buildings cannot be seen in those vistas). Strategic views include those (both panoramas and internal views), which are important for the preservation of the city's image, its cultural identity and its identification. The method is based on separating and protecting vistas as a popular criterion in a number of planning documents that determine cityscape development rules in Europe and in the world. The VPS puts together the main objectives of strategic views protection to determine height limits for planned buildings.

For small city areas the result of the VPS can be presented as a 3D image which is better suited for more intuitive interpretation. For larger areas ( $>$ ca. $5 \mathrm{~km} 2), 2 \mathrm{D}$ maps are the clearer presentation of the VPS result (Czyńska, Rubinowicz 2015, p. 142:6). With such 2D maps and color coding it is possible to mark height limits for new buildings in a city. The basis for VPS application is a digital 3D city model. The type of model used is decisive regarding accuracy of results and possibility of using the method (together with software for processing of the model).

\section{APPLIED 3D-CITY-MODELS}

The development of virtual imaging techniques applied to the city space fits into a wider formula of Industry 4.0. We are dazzled by new technological developments that enable us to use various interfaces (computer, tablet, mobile phone) to see 3D city images of an increasingly high resolution. For example, 3d-reality-mesh (Rubinowicz 2019b, p. 1016) used by Google. Linking of the city structure with its semantics and GIS data is provided by CityGML (Kolbe 2009), which introduces a universal standard for recording $3 \mathrm{D}$ city models. Additionally, VR techniques become increasingly popular. However, while using city models in urban and cityscape analyses, other parameters are important, parameters which focus less on 3D presentation and more on the precision of imaging.

In the study presented in the article, the following criteria were taken into consideration while selecting a relevant 3D model: a) availability of data, b) possibility of model processing, c) its validity, d) completeness (taking into account all major components of cityscape). Finally, LiDAR data were used, in par- 
Figure 1

DSM and DTM data

and

orthophotomaps

used in case study

for Gdańsk, Poland:

a) visualization of

large city area

(approx. 180km2)

developed using all

data, b)

visualization of

DSM for small city

area. Source: all

simulations made

with software

developed by

author a)
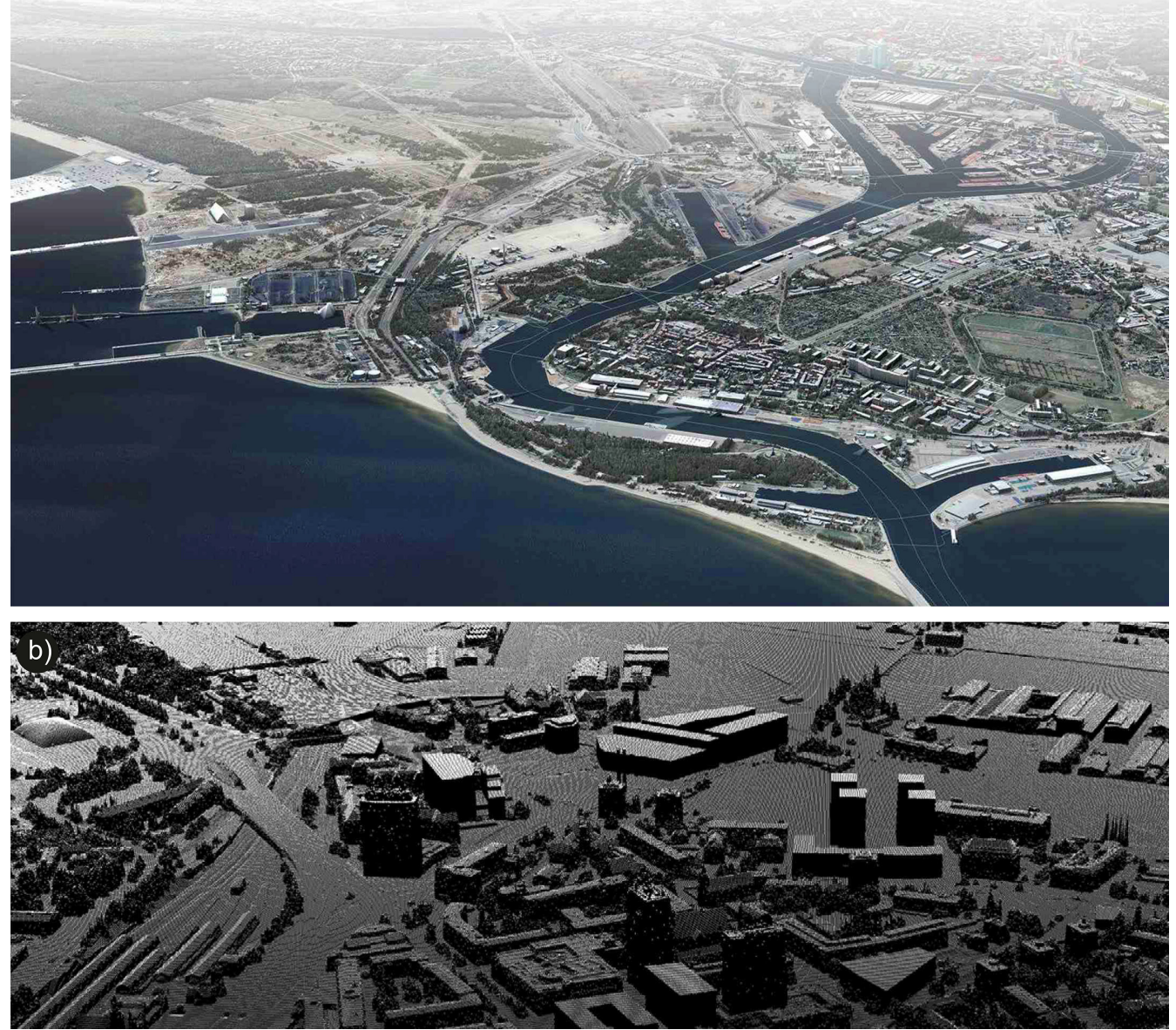

ticular DSM model and Digital Terrain Model (DTM). DSM with $50 \mathrm{~cm}$ mesh, and DTM with $1 \mathrm{~m}$ mesh. A complementary component was an orthophotomap $(50 \mathrm{~cm}$ terrain pixel). Such a 3D city model covers all components that are important for cityscape analysis (terrain, buildings and tall green) which are included in the model at the same level of accuracy.

Documentation, including DSM and DMT mod- els and orthophotomaps, has been popular in the world for many years. The precision of data has been growing accompanied by an inversely proportional trend regarding data collection cost. In Poland, required data have been developed for all larger cities in 2013. Such data are made available by the Main Office of Geodesy and Cartography free of charge for scientific purposes and against a small fee (ca. 0.50 
euro per $1 \mathrm{~km} 2$ ) for commercial use. Data can be downloaded or purchased on-line [2].

The visualization developed using DSM and DTM data and orthophotomaps for Gdańsk is presented in figure 1. The most important resource is the DSM model in the form of a point cloud. It precisely depicts the spatial structure of the city (figure 1b). The use of the model for visualization of the city and urban analysis has been discussed in other articles (Rubinowicz 2019b, Rubinowicz 2018). The methods and software enables to process large urban areas (at the moment up to $200 \mathrm{~km} 2$ ) while maintaining full resolution of the DSM model (figure 1a).

\section{CASE STUDY}

A study has been carried out for the city of Gdańsk, Poland, to assess the possibility of using the VPS method. In this case, the protection measure covered panoramas seen from the river of Motława. The analyzed sequence of views (of total length ca. 370m) from the Green Bridge (Zielony Most) and boulevards near the Spichrzów Island (figure 2a, 2d). Brama Żuraw, a historical facility and an icon of Gdansk (figure $2 b$ ) is a local dominant in the cityscape. Panoramas that can be seen from that section of the Motława River are protected by the Conservation Authority. This limits the height of new buildings that could otherwise stand out in the current skyline (figure 2b). A potential threat is posed by tall buildings planned in the former shipyard area and in the vicinity of the Polski Hak Quay in about $1.5 \mathrm{~km}$ from locations analyzed (figure 2c).

The VPS analysis covered an area of $25 \mathrm{~km} 2(5 \mathrm{~km}$ $x$ 5km). Calculations were based on the 2013 DSM city model (50cm mesh) as 3D-Mesh (200 million triangles). It was complemented with facilities built after 2013 and those which construction was in progress. Several options were considered regarding distribution and number of control points representing strategic views - 8, 14, 28, 57, 90, and 185 points. The basic VPS analysis used $50 \mathrm{~cm}$ mesh for 57 control points. For each point (every half a meter) and accuracy of $15 \mathrm{~cm}$, calculations defined the threshold height above which a prospective building facility can be seen in one of views studied.

Results of the VPS analysis is presented in the figure attached (figure 3). Height levels are marked by color coding. According to the study, the area to be protected by height control is very broad and of irregular shape. The analysis also indicates locations where at a close distance $(450 \mathrm{~m})$ a facility of $100 \mathrm{~m}$ in height cannot be seen. However, there are locations where distant $(>2 \mathrm{~km})$ and low-rising $(>20 \mathrm{~m})$ buildings can be seen in panoramas. The figure (figure $3 b$ ) presents the impact analysis for planned investment and shows visibility heights of particular architectural facilities.

\section{RESULTS \& DISCUSSION}

Results of the VPS study for Gdańsk can be compared with the previous VPS analyses for Dresden (Rubinowicz, Czyńska, 2015) and Szczecin (Rubinowicz 2019a). In the case of Dresden, although similar analyses focused on the protection of waterfront panoramas, the VPS was based on the CityGML model. The use of the DSM model, in the case of the study for Gdańsk discussed in the article, produced more accurate results in all spatial components of the city, including trees. Although the processing of the CityGML and DSM models differ and the geometrical complexity of the DSM model is much larger, the VPS emulation time was comparable in both instances. It is also possible to convert DSM to CityGML (Isikdag, Zlatanova 2009; Rubinowicz 2017) which widened the application of the VPS method and the use of various software.

The case study was carried out using $\mathrm{C}++$ software developed by the author. However, the analyses can be based on other software as well (CAD/GIS). The Gdańsk study analyzed various options of input parameters that are decisive regarding the accuracy of VPS simulations. It applied to two aspects: a) distance between test points - from ca. $50.0 \mathrm{~m}$ (in case of 8 points) to ca. $2.0 \mathrm{~m}$ (in case of 185 points) and b) VPS mesh resolution $(0.5 \mathrm{~m}, 1 \mathrm{~m}, 2 \mathrm{~m}, 5 \mathrm{~m}, 10 \mathrm{~m}, 25 \mathrm{~m}$, $100 \mathrm{~m})$. The smaller the distance between test points 
Figure 2

Strategic views in case study for

Gdańsk: a)

sequence of

strategic views (57

in this case); b)

panorama from

point no. 10 - red

line limits height of new buildings; $c$ ) aerial photograph with former shipyard area where new buildings are planned, including tall buildings; $d$ ) aerial photograph showing panorama along Motława River. Source: material by the author, aerial photographs from http://gdansk.ukosne.pl
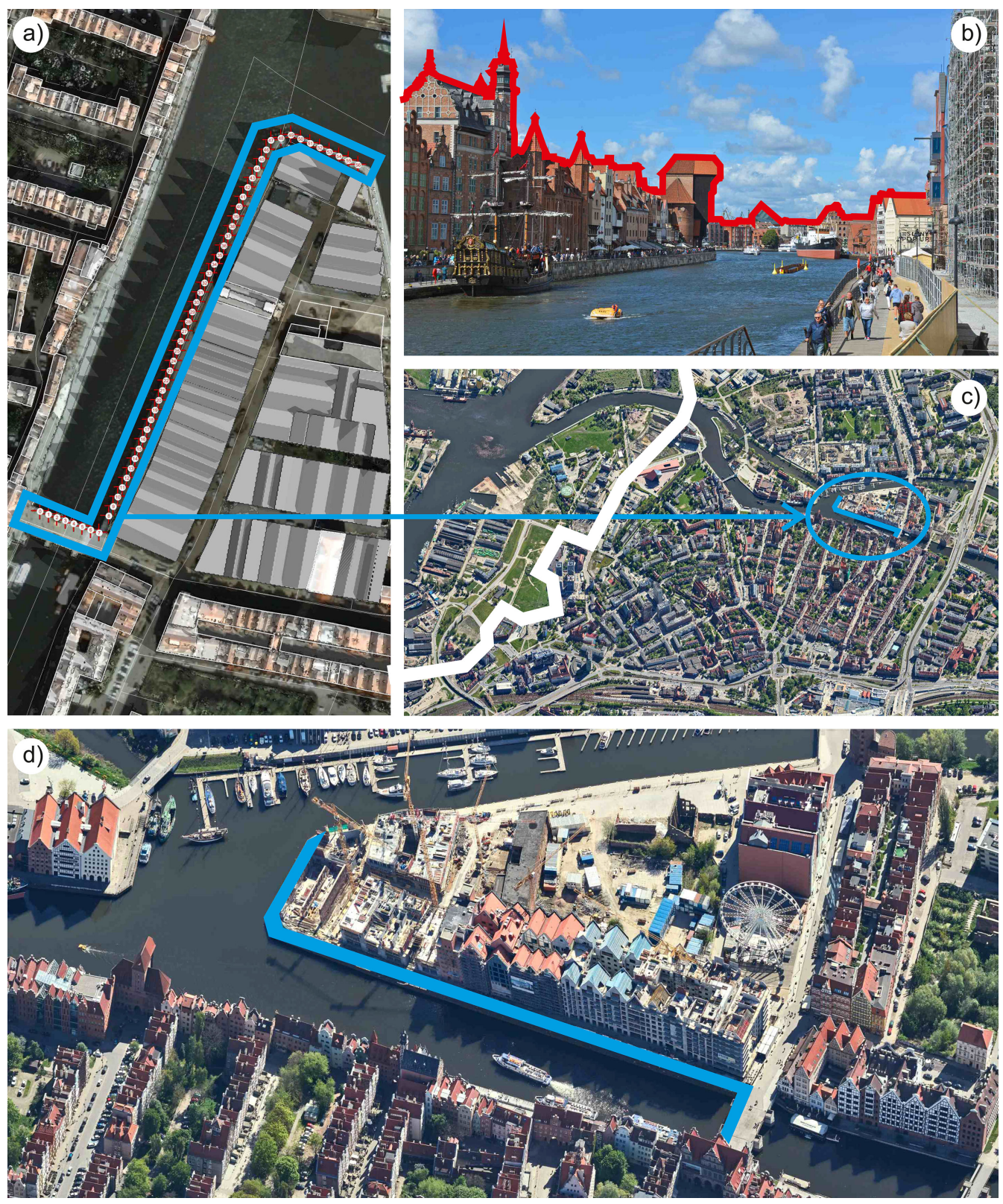


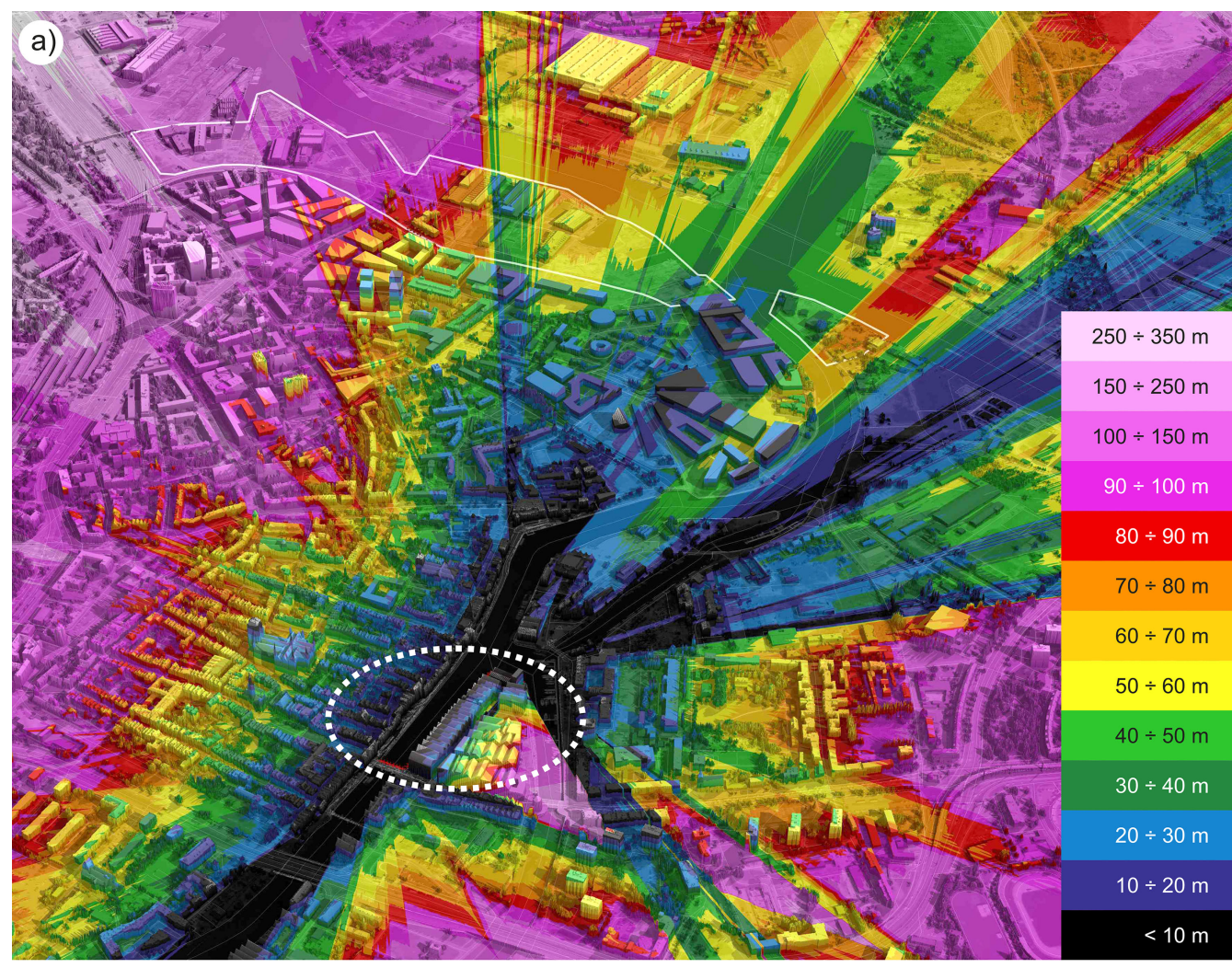

Figure 3

VPS analysis for

Gdańsk: a)

visualization of city

area showing

permitted height of

new buildings; $b$ )

visualization of

planned tall

buildings in

shipyard area and

Polski Hak Quay

which stand out

above the VPS

surface, and will be partly visible in

protected

panoramas. Source:

all simulations

made with software developed by

author

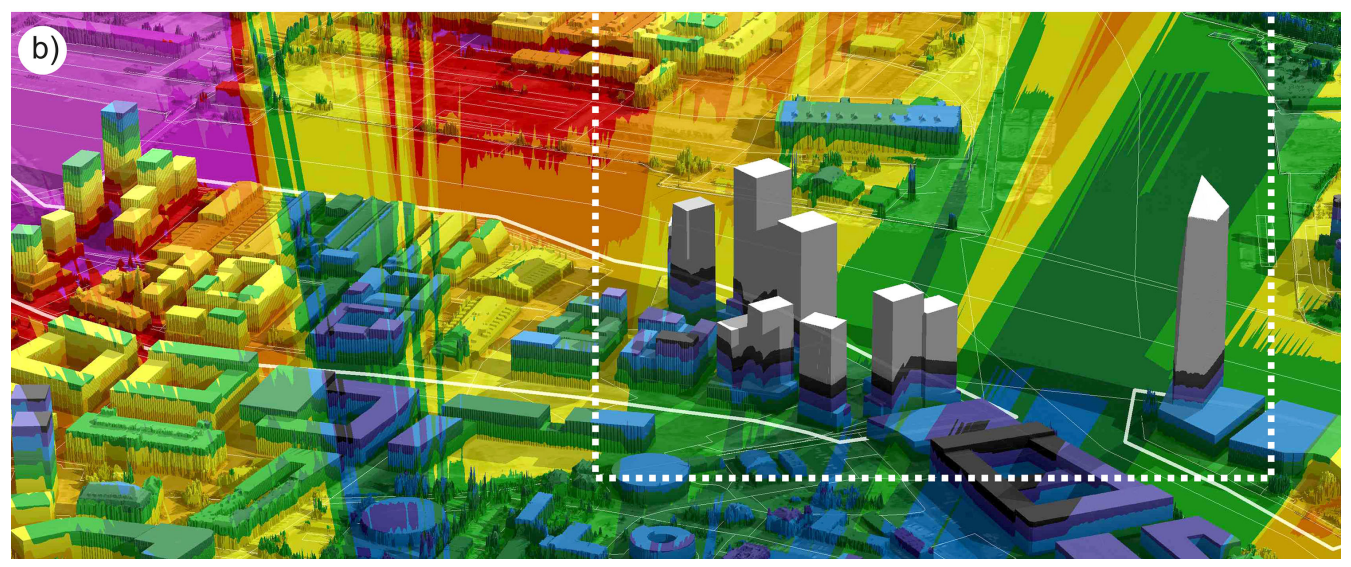

330 | eCAADe 37 / SIGraDi 23 - Data - BUILDING INFORMATION MODELLING 2 - Volume 2 
Figure 4

Analysis of input parameters for VPS case study for Gdańsk: a) lowest number of test points (8 points) and small VPS mesh resolution, b) largest number of test points (185 points) and small VPS mesh resolution, c) lowest number of test points (8 points) and high VPS mesh resolution, d) largest number of test points (185 points) and high VPS mesh resolution. Source: all simulations made with software developed by author

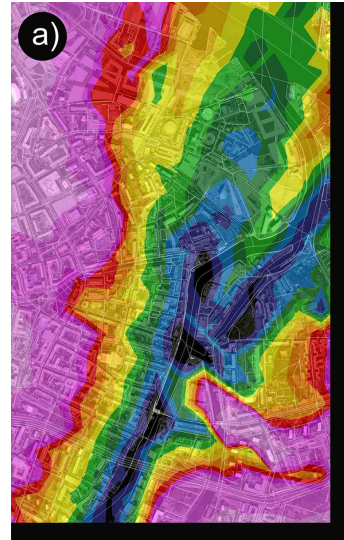

8 points, VPS_res: $100 \mathrm{~m}$

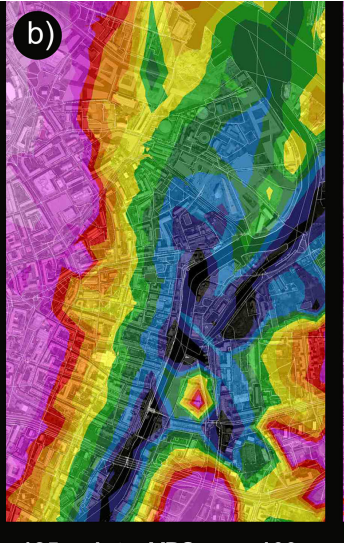

185 points, VPS_res: $100 \mathrm{~m}$

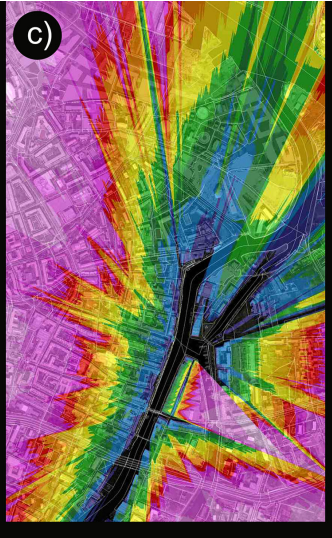

8 points, VPS_res: $1 \mathrm{~m}$

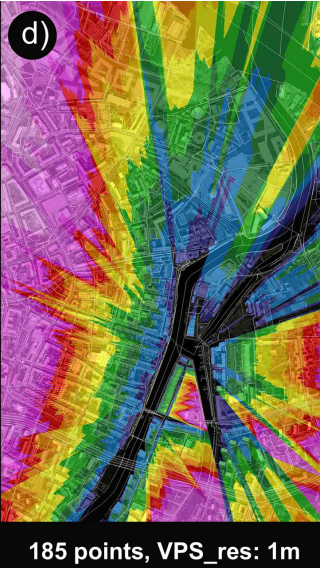

185 points, VPS_res: $1 \mathrm{~m}$ and the smaller the VPS mesh size, the more precise results are. Moreover, the selection of parameters for the simulation is crucial for the calculation time (depending on input parameters, it may take from several minutes to dozens of hours). Examples of VPS simulations for various (extreme) input parameters are presented in figure 4 . Thus, the following guidelines can be formulated, which might be helpful while applying the method using different software: a) city model needs to be as accurate as possible (DSM accuracy at least $0.5 \mathrm{~m}$ ), b) VPS resolution of about $2 \mathrm{~m}$ provides satisfactory results, c) to examine sequence of views, the distance between control points should not exceed ca. $8 \mathrm{~m}$.

Results of VPS method and DSM model are objective (geometrically unambiguous). However, they always need to be interpreted. A crucial issue is whether planned investment can be seen within panoramas and whether it is acceptable. In each case, the VPS enables to define those areas in the city where new investment requires more in-depth urban analysis. The VPS simulation defines general guidelines that can be further analyzed using digital techniques, e.g. using methods examining the impact of individual buildings on the cityscape, such as Visual Impact Size (VIS) (Czyńska 2015; Czyńska 2018).
Strategic views are one of key components of spatial planning as regards the protection of the cityscape. They are also basic input parameters for VPS analyses. The identification of strategic views can also be supported by digital techniques, e.g. the use of the WVEM method (Czyńska, Rubinowicz 2019). However, the identification of vistas to be protected often turns out to be insufficient. An example is the London View Management Framework [3], which determined 27 strategic views to be protected. The example shows that mere defining of views is not an efficient planning tool, since one of these 27 views for London was irreversibly lost [4]. The method described in the article enables to translate (aggregate) the protection scope for several strategic views into a VPS map which is easy to interpret. This creates a basis for the VPS application in urban planning.

\section{CONCLUSIONS}

The article presents the method used for the protection of a cityscape in waterfront views. Its application has been discussed based on the Case Study of Gdańsk, Poland. The study showed how new planned tall buildings can influence protected views from the Motława River. The analysis is based on the dedicated $\mathrm{C}++$ software. The article also 
presents guidelines which facilitate similar analyses using other tools (GIS/CAD). Although the VPS result is geometrically objective, it needs to be interpreted, in particular regarding possible consent to develop tall buildings in specific panoramas or their restrictive protection. In each case, the VPS enables to define areas in the city where new investment requires an indepth urban analysis. The method can be used in the process of spatial planning to harmonize the development of the cityscape and conservation of historical heritage. It defines the scope of strategic views protection in the form of a single map which determines building height limits in a city - possible to apply in the urban planning process.

\section{REFERENCES}

Caha, J. 2017, 'Representing and Exchanging 3D City Models with CityGML', in Ivan, I. (eds) 2017, Dynamics in Glscience, Lecture Notes in Geoinformation and Cartography, Springer International Publishing, pp. 17-29

Czyńska, K. 2015, 'Application of LiDAR Data and 3D-City Models in Visual Impact Simulations of Tall Buildings', Int. Arch. Photogramm. Remote Sens. Spatial Inf. Sci., XL-7(W3), pp. 1359-1366

Czyńska, K. 2018 'High precision visibility and dominance analysis of tall building in cityscape - on a basis of Digital Surface Model', Proceedings of the 36th eCAADe Conference 2018, Łódź, Poland, pp. 481-488

Czyńska, K. and Rubinowicz, P. 2015 'Visual protection surface method: Cityscape values in context of tall buildings', Proceedings of the 10th International Space Syntax Symposium, London, pp. 142:1-142:10

Czyńska, K. and Rubinowicz, P. 2019, 'Classification of cityscape areas according to landmarks visibility analysis', Environmental Impact Assessment Review, 76, pp. 47-60

Danese, M., Nolè, G. and Murgante, B. 2009, 'Visual Impact Assessment in Urban Planning', in Murgante, B., Borruso, G. and Lapucci, A. (eds) 2009, Geocomputation and Urban Planning, Springer-Verlag, Berlin Heidelberg, p. 133-146

Isikdag, U. and Zlatanova, S. 2009, 'Towards defining a framework for automatic generation of buildings in CityGML using building information models', in Lee, J. and Zlatanova, S. (eds) 2009, 3D Geo-Information Sciences. Lecture Notes in Geoinformation and Cartography, Springer, Heidelberg
Kolbe, T. 2009, 'Representing and Exchanging 3D City Models with CityGML', in Lee, J. and Zlatanova, S. (eds) 2009, 3D Geo-Information Sciences, Springer, Berlin-Heidelberg, pp. 15-31

Rubinowicz, P. 2017, 'Generation of CityGML LoD1 city models using BDOT10K and LiDAR data', Space \& Form, 31, pp. 61-74

Rubinowicz, P. 2018 'Application of Available Digital Resources for City Visualisation and Urban Analysis', Proceedings of the 36th eCAADe Conference 2018, Łódź, Poland, pp. 595-602

Rubinowicz, P. 2019a 'Application of the Visual Protection Surface Method (VPS) for Protection of Landscape Interiors within a City', Proceedings of World Multidisciplinary Civil Engineering-ArchitectureUrban Planning Symposium (WMCAUS 2018), IOP Conf. Series: Materials Science and Engineering 471, Prauge

Rubinowicz, P. 2019b 'Visualisation of DSM as 3D-Mesh for Urban Analyses', Proceedings of the 18th International Conference on Geometry and Graphics, 40th Anniversary, Milan, Italy, pp. 1013-1022

Rubinowicz, P. and Czyńska, K. 2015, 'Study of City Landscape Heritage Using Lidar Data and 3d-City Models', Int. Arch. Photogramm. Remote Sens. Spatial Inf. Sci., XL-7(W3), pp. 1395-1402

[1] http://www.skyscrapercenter.com/x/8700681

[2] https://pzgik.geoportal.gov.pl/imap/

[3] https://www.london.gov.uk/what-we-do/planning/i mplementing-london-plan/planning-guidance-and-pra ctice-notes/london-view-management

[4] https://www.architectsjournal.co.uk/news/outrageover-somskyscraper-that-destroys-view-of-st-pauls/100 15058.article 